\title{
Editorial: New Journal for Publishing Relevant Research in Control, Automation and Electrical Systems
}

\author{
Ivan Nunes da Silva
}

Published online: 29 March 2013

(C) Brazilian Society for Automatics-SBA 2013

The Journal of Control, Automation and Electrical Systems (JCAES) is a new bimonthly publication sponsored by the Brazilian Society for Automatics (SBA).

The SBA was established in 1975 as a scientific organization to promote the Science and Engineering of Automation and Control in Brazil and to be a leading forum for researchers, students and professionals working in the various fields of Control and Automation. Currently the SBA has over 700 members in Brazil (professionals, students, and organizations) and is responsible for organizing the major South-American academic event in the field of automatics, the Brazilian Congress for Automatics (CBA), a biannual event that attracts around 1,000 participants, as well as the Brazilian Symposium on Intelligent Automation (SBAI). Furthermore, the SBA co-sponsors many other events promoting Automation and Control activities in Brazil. Since 1987 the SBA has been responsible for the affiliated journal Controle \& Automação (Control \& Automation Journal), the most important scientific journal in the control and automation area in Brazil, which has seen the publication of 23 volumes (since 1987), and is considered to be one of the leading scientific journals in Latin America.

As a result, the JCAES has inherited a high profile and long academic tradition since it will now be replacing Controle \& Automação, distinguished by the fact that the new Journal will be truly international. The mission of the JCAES is to publish original research papers, as well as tutorials pertaining to alternative sources of energy, automation systems, circuits and systems, control theory and applications, discrete event systems, electrical machines and drives, electric power systems, electronic and biomedical instrumentation, energy

I. N. da Silva $(\varangle)$

Department of Electrical and Computer Engineering, University of São Paulo_-USP/EESC/SEL, CP 359, São Carlos, SP 13566-590, Brazil e-mail: insilva@sc.usp.br efficiency, intelligent systems, mechatronic systems, microgrids and intelligent networks (smart grids), power electronics, robotics, signal processing, systems identification and optimization, and education in control, automation, robotics and mechatronics. Contributions are therefore welcome on research, development and/or innovation in any area of science or technology impacting on automation.

The foundation of the JCAES reflects the quality of the articles published in this first issue, which make significant technical and scientific contributions to the areas of control, automation and electrical systems as a whole. In addition, extended versions of the best papers presented at the $\mathrm{X} \mathrm{SBAI}^{1}$, the Brazilian Symposium on Intelligent Automation, are also included in this inaugural issue. This symposium is the main scientific event on intelligent automation in Latin America, having been held biennially since 1991. The X SBAI was held from 18 to 21 September 2011, in São João del Rei (Brazil). The event witnessed an important growth in the number of submissions and participants in relation to previous editions; the 368 proposals received, of which 226 were accepted, represented an increase of about 48 and $18 \%$, respectively. The revision process required the work of 57 TPC members and 592 reviewers. Authors of papers selected from those presented at the symposium were then invited to submit an extended version for this inaugural issue. The selection criteria were the scores obtained by the papers in the review process, as well as the evaluations of the Chairs from the 45 scientific sessions of the X SBAI. A total of 18 papers were selected and evaluated in the regular review process of the Journal, of which only 7 were approved for publication.

\footnotetext{
$\overline{1}$ The SBAI was organized by Valter J. S. Leite (Program Chair, CEFET/MG), Erivelton G. Nepomuceno (General Chair, UFSJ) and Márcio F. S. Barroso (Operating Committee, UFSJ).
} 
For forthcoming issues of the Journal, I cordially invite researchers in related areas to submit only your best, truly innovative and rigorous work to the Journal of Control, Automation and Electrical Systems. Our goals are to publish theoretical developments and application studies on highly promising themes involving state-of-the-art research; to offer a truly interdisciplinary forum in industrial automation, intelligent systems, robotics, control theory and electrical systems; to offer a highly respected and reliable international forum and efficient peer-review; to guarantee an excellent response time from submission to first decision; and to publish articles online within 30 days of acceptance.

Finally, I hope you enjoy reading this inaugural issue of the Journal of Control, Automation and Electrical Systems. I look forward to receiving your future contributions, whether as author, reader, or volunteer. We shall always be here to listen to your opinions and suggestions, and will try our best to address your needs promptly. 